\title{
“Oral Menopause” - Do you know this Phenomenon?
}

\section{Bruckmann C* \\ Medical University Vienna, School of Dentistry, Austria}

*Corresponding author: Corinna Bruckmann, MD, MSc, Medical University Vienna, School of Dentistry, Sensengasse 2a 1090 Vienna Austria, Austria, Tel: +431400704785; E-mail: corinna.bruckmann@meduniwien.ac.at

\section{Conceptual \\ Volume 2 Issue 1}

Received Date: December 02, 2017

Published Date: January 26, 2018

DOI: $10.23880 /$ whsj-16000106

\section{Abstract}

Patients as well as therapists, even dental professionals, are not fully aware of the fact that menopausal oral problems can seriously impair quality of life. However, hormone receptors in the oral mucosa may cause dry mouth and mucous membrane pain due to menopausal hormone changes. Some disease entities such xerostomia, oral lichen planus, or "Burning Mouth Syndrome" are significantly more common during and after menopause and present problems for patients and therapists alike. Increased knowledge, awareness and structured approach could lead to better interdisciplinary communication and therapy.

Keywords: Menopause; Oral Lichen Planus; Xerostomia; Burning Mouth Syndrome

Abbreviations: QoL: Quality of Life; HRT: Hormone Replacement Therapy; OLP: Oral Lichen Planus; BMS: Burning Mouth Syndromes.

\section{Definitions and Biological Background}

Menopause refers to the years of hormonal change before and after the last spontaneous menstruation (usually between the $45^{\text {th }}$ and $55^{\text {th }}$ year of life), thus ending the woman's fertility phase [1]. The menopausal transition precedes menopause by several years and is usually characterized by irregularity of the menstrual cycle. For many women this period in their life is associated with a variety of predictable symptoms and conditions such a shot flashes and nicht sweats. This may lead to severe impairment of quality of life (QoL) [2,3] and depressive moods [4]. After menopause, genitourinary symptoms predominate. Dryness of the vaginal mucosa due to vulvovaginal atrophy may not only cause dyspareunia but also deterioration of QoL [5].

The impact of menopausal hormone changes on the oral system seems plausible for several reasons: oral mucosa and vaginal epithelium show great histological similarity in terms of keratinization and lipid distribution [6]. Further, sex hormone receptors have been detected in the oral mucosa and salivary glands [7]. Both the sensation of pain and colonization with microorganisms are subject to hormonal influences $[8,9]$. Pathogens find a potential port of entry in the oral mucosa (especially via the gingival sulcus). Although there is a homeostasis when the immune system is intact, inflammatory reactions can easily occur.

Recent reviews often describe clinical manifestations such as reduction of salivary flow, dry mouth, reduction of epithelial keratinization, redness or bleeding during cleaning or probing in peri- and postmenopausal women $[6,10,11]$.

However, postmenopausal hormone imbalances also have an impact on oral quality of life: a very recent cross-sectional study of 97 female dental hygienists (age 40-59) assessed personal wellbeing and correlated it with oral and systemic parameters: estrogen deficiency in blood serum was correlated with decreased salivation and higher depression scores [12].

\section{Common Complaints}

Female patients referred to the "oral mucosa unit" of the Medical University Vienna, School of Dentistry, often complain nonspecific symptoms: most often "burning in 
the mouth", sometimes representing as mucosal redness or erosion. Very often anamnesis reveals a multitude of unsuccessful therapy attempts: e.g.: various antiseptic mouth washes, antibiotics, antimycotics. Peri- and postmenopausal patients report significantly more often oral malaise than their premenopausal peers. A structured survey and examination, although not yet proposed by any professional society, seems necessary to better understand the problems of this patient group (Table 1, after $[13,14])$. Some typical problems will be described in further detail below.

\section{Xerostomia}

Saliva might be annoying for the restorative dentist but in fact proves to be the most important factor for maintaining oral health. Hormone status or hormone replacement therapy (HRT) [11], fluid intake, smoking, stress and medication have an influence on saliva quality and quantity. Decrease of both flow rate and quality is known to have negative effects on teeth (lack of remineralization, caries risk). Dehydration of the mucous membranes and changes in saliva composition may lead to reduced mucosal defence, overgrowth of candida, and bad breath.

Xerostomia is defined as salivary flow of $<0.5 \mathrm{ml} / \mathrm{min}$ (stimulated saliva) (Figure 1). Therapeutically - after an encompassing medical history - adequate moistening of the oral mucosa is the goal (Table 1). However, a feeling of "dry mouth" is not always consistent with the measured flow rate(15) thus psychological components should also be taken into account.

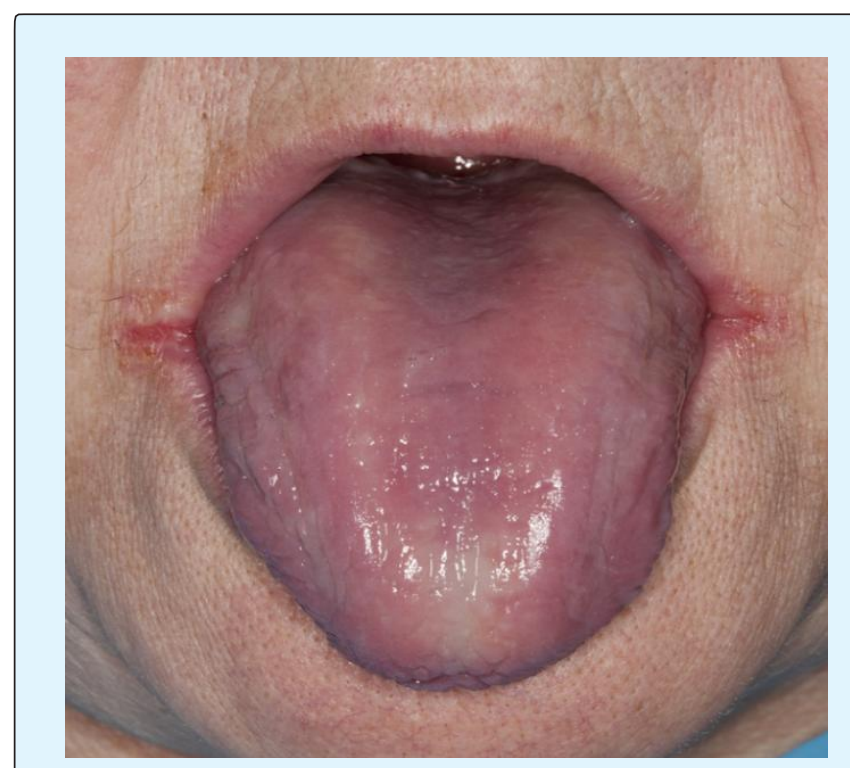

Figure1: Severe xerostomia, atrophic tongue, perlèche (C) School of Dentistry, Vienna).

\begin{tabular}{|c|c|}
\hline Assessment & Consequences \\
\hline Patient history & Prophylaxis / therapy \\
\hline Menstrual cycle? Climacteric symptoms? & Regular professional mechanical tooth cleaning \\
\hline Depression? & Chemical plaque control (avoid alcohol) \\
\hline Smoking? & Regular fluoride application \\
\hline Eating disorders? & Avoid sodium lauryl sulfate (SLS) \\
\hline Medications (with effect on salivation)? & \\
\hline HRT / Bisphosphonates / Denosumab® / Calcium / Vitamin D? & \\
\hline Dry mouth? Burning tongue? & \\
\hline Vaginal problems? & \\
\hline Fluoride application? & \\
\hline Mouthwash application: with alcohol? & \\
\hline \multicolumn{2}{|l|}{ Intraoral examination } \\
\hline Saliva: quantity, quality & Counseling \\
\hline Mucous membranes & Smoking cessation \\
\hline \multirow[t]{2}{*}{ Periodontal / dental conditions } & Sufficient fluid intake \\
\hline & Calcium and Vit. D intake \\
\hline
\end{tabular}

Table 1: Structured path for patient guidance.

The salivary flow rate can quickly and easily be determined: A paraffin pellet is chewed for 5 minutes and the saliva produced collected in a vessel. The saliva is then taken up with a $5 \mathrm{ml}$ syringe. If this can be completely filled, the salivary flow rate is at least 1 $\mathrm{ml} / \mathrm{min}$ and thus normal. If xerostomia is proven by a lower flow rate, it is important to follow a structured procedure to alleviate symptoms (Table 2). 


\section{Women's Health Science Journal}

\begin{tabular}{|c|c|}
\hline What & Why/how \\
\hline sufficient fluid intake & $>1,51 /$ day: water or sugar-free tea; suck ice cubes \\
\hline no tobacco, alcohol, caffeine & oral dryness \\
\hline no soft drinks & high sugar content: erosive potential \\
\hline avoid: too sweet, too salty, too spicy & $\begin{array}{c}\text { osmotic effect of sugar/salt; local effects of } \\
\text { capsicum }\end{array}$ \\
\hline $\begin{array}{c}\text { xylitol } \\
\text { lozenge }\end{array}$ & $4-5 \times 5 \mathrm{mg} /$ day \\
\hline stimulate salivary glands: sugar-free chewing gum or & Gum Hydral@, BioXtra $₫$, dentaidute (hyaluronic acid or methylcellulose) \\
\hline severe cases: pilocarpine hcl tablets (caveat: side effects) & \\
\hline
\end{tabular}

Table 2: Interventions in case of xerostomia

\section{The Primary/Idiopathic "Burning Mouth Syndrome" (BMS): A Diagnostic and Therapeutic Challenge}

Patients complain a chronic, burning, sore feeling (stomatodynia) especially in the front 2 thirds of the tongue and the surrounding mucous membranes. Typical is the daily occurrence, lasting for more than 2 hours per day and more than 3 months. However, any clinical correlate is missing, leading to frequent mismanagement. Sex ratio is 7: 1 for women, mean age of occurrence 50-60 years, suggesting a connection with the menopause. Significantly higher levels of folliclestimulating hormone, more adverse life events, more tendencies for somatization and higher anxiety scores are found [8]. Symptoms range from mild tingling to severe pain. Also dry mouth, numb feeling and disorders of the taste sense (dysgeusia) are reported. Current theories describe a neuropathic aetiology of primary BMS. Secondary BMS must be excluded by differential diagnosis: local and systemic infectious, inflammatory, traumatic, or neoplastic processes, iron, zinc, vitamin B12 or folic acid deficiency, diabetes, hypothyroidism, allergies, autoimmune diseases, anxiety disorders / depression and all other typical causes of xerostomia $[16,17]$.

Therapy proves challenging, as there are no guidelines. The diagnosis, even if finally found, is not very tangible for the patients. These are usually anxious, depressed and frustrated by past unsuccessful, often expensive treatments and unfulfilled healing promises. Therefore, it is particularly important for the therapist to convey understanding, although no overt objective changes are visible. Psychological support, topical application of clonazepam or systemic anticonvulsive drugs has been suggested [18].

\section{Oral and Genital Sores: Oral Lichen Planus (OLP)}

OLP predominantly affects women and often manifests itself in the $4^{\text {th }}$ to $6^{\text {th }}$ decade. A T-cell mediated autoimmune mechanism is proposed. A prevalence of up to $4 \%$ renders OLP one of the most common oral mucosal disorders [19]. The course is chronic or subacute, most often the mucous membranes of both cheeks are symmetrically affected. Reticular forms are usually incidental findings and mostly require no therapy. However, patients with erosive, atrophic or bullous forms suffer from severe impairment of QoL due to severe pain, which often leads to avoidance of eating or oral hygiene. Psychologic evaluation of OLP patients show them to be more prone to depression and excessive anxiety [20].

In addition to the involvement of oral mucous membranes, involvement of the skin (15\%) and the extra oral mucosa (20\%) is reported ("vulvovaginal gingival" or "penogingival" syndrome, esophageal LP) [21]. The diagnosis should be confirmed histologically and by direct immunofluorescence. In order to avoid unnecessary biopsies, concise taking of patient history which also takes into account gynaecological findings is of utmost importance. In the case of positive biopsy the appropriate communication with the gynaecologist should be coordinated.

Therapy, predominantly symptomatic, consists in elimination of irritant factors (rough fillings, spicy foods, poor oral hygiene, and toothpaste with sodium lauryl sulfate), topical application of hyaluronic acid and corticosteroids in the case of acerbation. Due to a (low) malignancy potential, which is shown especially in erosive and bullous forms, a regular check-up (every 3 6 months) is recommended. Here, too, the focus is on providing good advice to patients on "living with the disease". In severe or refractory cases, systemic immunosuppression has to be considered.

\section{Conclusion}

Oral health in postmenopausal women might be affected due to hormonal dysbalance. Dental, mucosal and periodontal problems occur more often and need more attention followed by appropriate and individualized care. Also, reduction of QoL is to have more impact due to higher life expectancy [22]. Unfortunately, till today only a limited number of well 
designed studies has dealt with the effects of menopause and knowledge even among specialists (oral professionals and gynaecologists) is scarce. Although not all aspects of hormonal change (or HRT) on postmenopausal oral health have yet been elucidated, interdisciplinary collaboration could already today ensure better patient care and avoid pointless and expensive polypragmasia. Guidelines for structured patient management could facilitate better clinical practice.

\section{References}

1. McKinlay SM, Brambilla DJ, Posner JG (2008) The normal menopause transition. Maturitas 61(1-2): 416.

2. Deecher DC, Dorries K (2007) Understanding the pathophysiology of vasomotor symptoms (hot flushes and night sweats) that occur in perimenopause, menopause, and postmenopause life stages. Arch Womens Ment Health 10(6): 247257.

3. Utian WH (2005) Psychosocial and socioeconomic burden of vasomotor symptoms in menopause: a comprehensive review. Health Qual Life Outcomes 3: 47 .

4. Zeleke BM, Bell RJ, Billah B, Davis SR (2017) Vasomotor symptoms are associated with depressive symptoms in community-dwelling older women. Menopause 24(12): 1365-1371.

5. Pinkerton JV, Bushmakin AG, Komm BS, Abraham L (2017) Relationship between changes in vulvarvaginal atrophy and changes in sexual functioning. Maturitas 100: 57-63.

6. Thompson IO, van der Bijl P, van Wyk CW, van Eyk AD (2001) A comparative light-microscopic, electron-microscopic and chemical study of human vaginal and buccal epithelium. Arch Oral Biol 46(12): 1091-1098.

7. Mascarenhas $\mathrm{P}$, Gapski R, Al-Shammari K, Wang HL (2003) Influence of sex hormones on the periodontium. J Clin Periodontol 30(8): 671-681.

8. Aggarwal M, Puri V, Puri S (2012) Effects of estrogen on the serotonergic system and calcitonin gene-related peptide in trigeminal ganglia of rats. Annals of neurosciences 19(4): 151-157.

9. Domingues RS, Ferraz BF, Greghi SL, Rezende ML, Passanezi E, et al. (2012) Influence of combined oral contraceptives on the periodontal condition. Journal of applied oral science 20(2): 253-259.
10. Irvine EJ, Zhou Q, Thompson AK (1996) The Short Inflammatory Bowel Disease Questionnaire: a quality of life instrument for community physicians managing inflammatory bowel disease. CCRPT Investigators. Canadian Crohn's Relapse Prevention Trial. Am J Gastroenterol 91(8): 1571-1578.

11. Mahesh DR, Komali G, Jayanthi K, Dinesh D, Saikavitha T, et al. (2014) Evaluation of Salivary Flow Rate, $\mathrm{pH}$ and Buffer in Pre, Post \& Post Menopausal Women on HRT. Journal of Clinical and Diagnostic Research 8(2): 233-236.

12. Yoshida N, Sugimoto K, Suzuki S, Kudo H (2018) Change in oral health status associated with menopause in Japanese dental hygienists. Int J Dent Hyg 16(1): 157-164.

13. Frutos R, Rodriguez S, Miralles-Jorda L, Machuca G (2002) Oral manifestations and dental treatment in menopause. Med Oral 7(1): 26-30.

14. Meurman JH, Tarkkila L, Tiitinen A (2009) The menopause and oral health. Maturitas 63(1): 56-62.

15. Minicucci EM, Pires RB, Vieira RA, Miot HA, Sposto MR (2013) Assessing the impact of menopause on salivary flow and xerostomia. Aust Dent J 58(2): 230-234.

16. Spanemberg JC, Rodriguez de Rivera Campillo E, Salas EJ, Lopez Lopez J (2014) Burning Mouth Syndrome: update. Oral Health Dent Manag 13(2): 418-424.

17. Nasri-Heir C, Zagury JG, Thomas D, Ananthan S (2015) Burning mouth syndrome: Current concepts. J Indian Prosthodont Soc 15(4): 300-307.

18. Silvestre FJ, Silvestre-Rangil J, Lopez-Jornet $P$ (2015) Burning mouth syndrome: a review and update. Rev Neurol 60(10): 457-463.

19. Kurago ZB (2016) Etiology and pathogenesis of oral lichen planus: an overview. Oral Surg Oral Med Oral Pathol Oral Radiol 122(1): 72-80.

20. Dvorak G, Monshi B, Hof M, Bernhart T, Bruckmann C, et al. (2015) Gender aspects in oral health-related quality of life of oral lichen planus patients. International journal of stomatology \& occlusion medicine 8(2): 33-40.

21. Lucchese A, Dolci A, Minervini G, Salerno C, D DIS, Minervini G, et al. (2016) Vulvovaginal gingival lichen planus: report of two cases and review of literature. Oral Implantol (Rome) 9(2): 54-60.

22. WHO (2017) Life expectancy. 